\title{
Rising asthma admissions and self referral
}

\author{
J STORR, ${ }^{*}$ E BARRELL, $\dagger$ AND W LENNEY† \\ ${ }^{*}$ City Hospital, Nottingham and †Royal Alexandra Hospital for Sick Children, Brighton
}

\begin{abstract}
SUMmary An eight fold rise in asthma admissions to the Royal Alexandra Hospital for Sick Children, Brighton occurred over the 15 year period 1971-85. The cause was an increase in the number of children seen, rather than increased readmission. The initial rise was associated with the introduction of nebulised salbutamol in 1976. The children concerned were mainly over 5 years old. Three years later came a larger influx of younger children. Circumstances leading to admissions were examined in a prospective study over a one year period. There were 605 admissions, $437(72 \%)$ were self referrals. The commonest reason parents gave for preferring hospital treatment was the availability of nebuliser treatment.
\end{abstract}

\begin{abstract}
A $167 \%$ rise in child asthma admissions in the South West Thames region between 1970 and 1978 was described by Anderson et al. ${ }^{1} \mathrm{He}$ found that there had been a shift in the balance of care towards the hospital largely caused by an increase in self referrals. There was little change in the severity on admission, and an inadequacy of ambulatory care was postulated. Khot $e t$ al found that admissions for the whole of England and Wales had trebled between 1975 and $1981 .^{2}$ The similarity of the monthly profiles, nationally, suggested the operation of 'major trigger factors.' Mitchell reviewed international trends in 1985 and found a striking rise in all countries examined. ${ }^{3}$ Although the major change was the increase in the number of individual patients admitted, he concluded that a rise in asthma incidence could only account for part of the increase.

Increased admissions for asthma may result from increased incidence or severity of disease, an increased tendency to seek medical help for conditions previously tolerated, increased hospital referral by general practitioners, increased self referral to casualty departments, or an increased tendency of medical officers to admit. ${ }^{4}$ Child asthma admissions in the Brighton area have risen as elsewhere, and have continued to rise. Criteria for admission in Brighton have not changed: children are admitted when symptoms or poor response to bronchodilator treatment indicate that intensive treatment or observation are required. Two surveys were therefore undertaken: a retrospective survey of admission trends and changes in management, and a prospective survey over a one year period to investigate the frequency of self referral and parental expectations of hospital treatment.
\end{abstract}

\section{Methods}

RETROSPECTIVE SURVEY

Details of all asthma admissions to the Royal Alexandra Hospital for Sick Children, Brighton were obtained from Hospital Activity Analysis for the years 1973-85. The data consisted of dates of birth, admission and discharge, sex, and hospital number, permitting identification of individual patients. The data were transferred electronically to a BBC microcomputer for analysis and numbers were checked for accuracy against existing hospital records. Rates per 1000 population allowed for admissions from outside the area. Data for 1971 and 1972 were derived from hospital records. For comparison, data were obtained from hospital records on admissions for bronchiolitis and wheezy bronchitis.

Information on treatment in hospital was known for all patients in 1985; for previous years it was derived from a sample of hospital notes covering 496 admissions. Random selection in each year was attempted but is not guaranteed owing to missing notes. Larger samples were used for years of changing trends: sampling was continued for each year until a set of stable averages was obtained, and accuracy was checked by the jackknife (data splitting) technique. Also obtained was information on casualty attendance (from 1975 onward) and on overall admission rate (from 1973).

The data for admission were sorted by date of admission, and by patient in order of date of birth. Identification of individual children provided, among other things, data on readmissions. The following definition of readmission rate was chosen 
so that trend could be examined over the longest possible time period: this was the percentage admissions in a calendar year where there had been a previous admission in the past natural year. A $60 \%$ readmission rate would therefore indicate that $60 \%$ had a previous admission within 365 days.

Trends for admission rate, age distribution, length of admission, and hospital treatment were calculated and plotted by computer. Significance was determined from the standard error except for admissions where the $\chi^{2}$ test was used. Temporal associations were explored by multivariate analysis and plotting residuals allowing, for example, change in median length of admission to be examined after accounting for the possible effects of changes in therapeutic practice.

\section{PROSPECTIVE SURVEY}

Data were collected prospectively on children with asthma admitted in the one year period March 1985 to March 1986. There were 605 admissions. Parents of 386 of the children who were admitted (64\%) were interviewed in person by EB or JS; the use of two interviewers directly concerned in the study was unavoidable. The remaining parents were sent a postal questionnaire which 135 returned and 84 did not. Data were therefore available on $521(86 \%)$. The questionnaire covered past, current, and family history, medication, contact with general practitioner, and expectations of hospital treatment. Parental expectations were determined as far as possible without leading questions.

\section{Results}

\section{RETROSPECTIVE STUDY}

An eight fold rise in admissions occurred over the entire period 1971-85 (fig 1). The rise occurred in two stages: first a moderate rise in admissions of

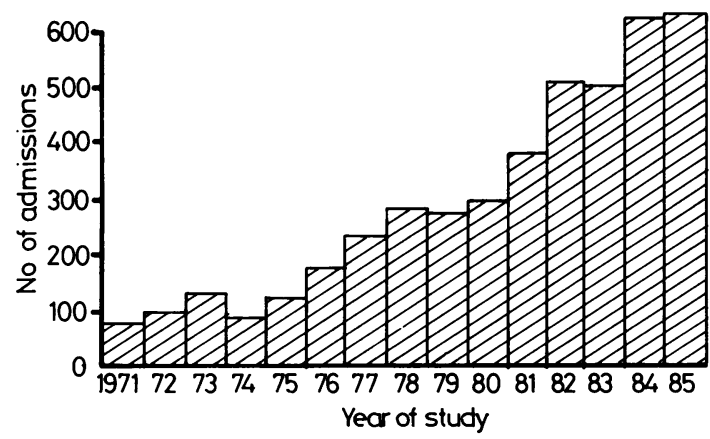

Fig 1 No of children with asthma admitted to the Royal Alexandra Hospital each year. school age children (fig 2a), and later a massive rise in children of preschool age (fig $2 \mathrm{~b}$ ). The age profile underwent an appreciable change as a result (fig 3 ). Median age rose from $5 \cdot 3$ to $7 \cdot 1$, then fell to 4.4 years.

The initial rise, which started in 1976, closely followed the introduction of nebulised salbutamol. This advent had a considerable effect on other treatment (fig 4). Oral bronchodilators were rapidly supplanted, and the use of croupettes and medications having a sedative effect (promethazine, trimeprazine, chloral, chlorpromazine, phenobarbitone) declined sharply. Corticosteroid use fell from over $50 \%$ to $10 \%$, with a gradual recovery to about $30 \%$ over several years.

The rise in admissions of younger children followed a similar pattern to that of the older children, but was larger, and occurred more than three years later. There was no obvious contemporary precipitating factor. An increasing use of the hospital casualty department for all conditions was evident in attendance rates over the period: 2823 in 1975, 3595

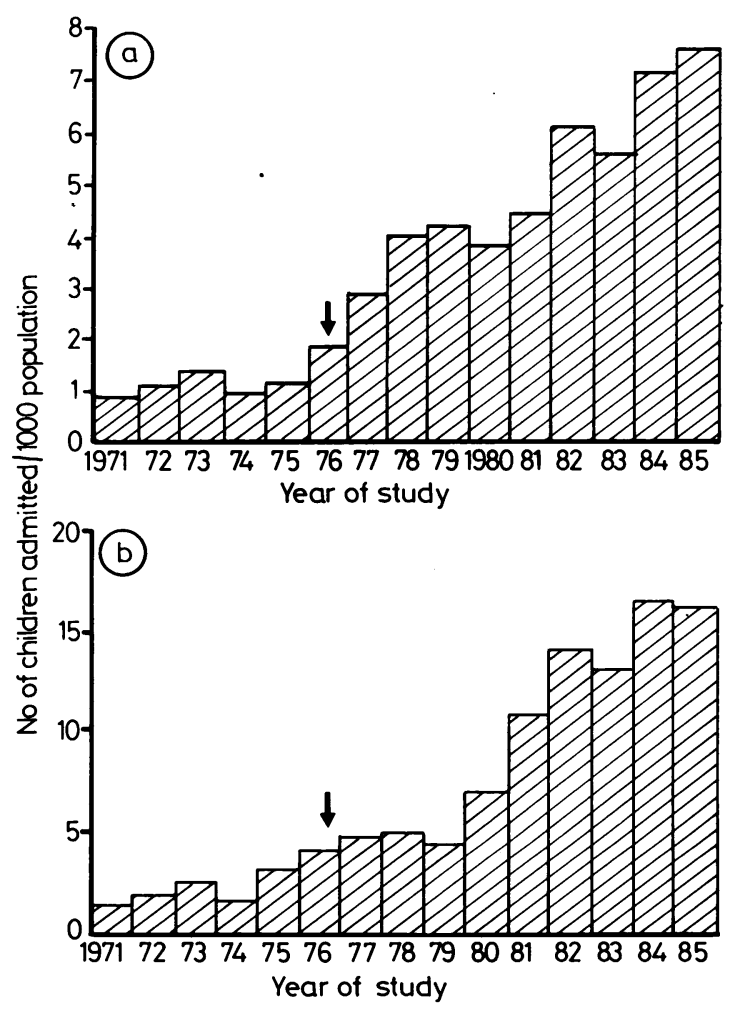

Fig 2 No of children aged (a) 5-14 years and (b) 0-4 years admitted per 1000 population in the same age range. The arrow indicates the $50 \%$ point in the introduction of nebulised salbutamol. 


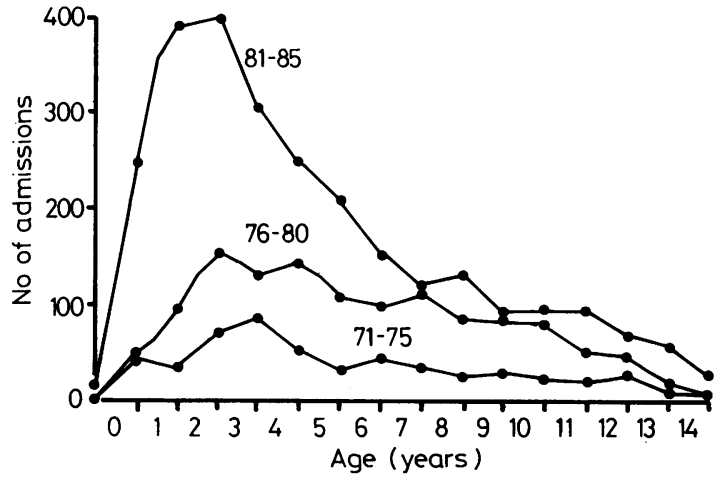

Fig 3 Changing age distribution for admissions for asthma in three five year periods: 1971-5, 1976-80, 1981-5. Rising admissions are evident, as well as a noticeable increase in the number of younger children admitted in the most recent period.

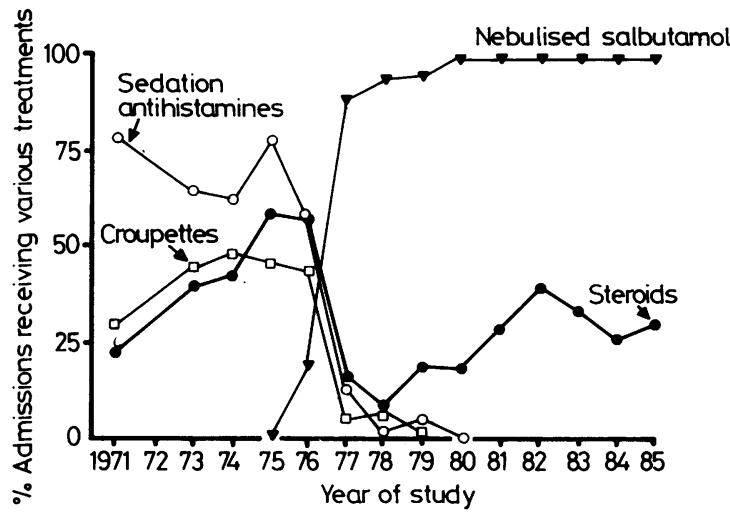

Fig 4 Percentage of admissions for asthma receiving nebulised salbutamol in each year and associated changes in other treatments. Steroids were either hydrocortisone or prednisolone.

in 1980 , and 5166 in 1985 . The age distribution of non-asthmatic children, however, did not show any consistent change, the median age remaining constant at 16 months.

The rise in asthma admissions was almost entirely due to an increase in the number of asthmatic children presenting to hospital: there was a similar eight fold rise in the number of first admissions for asthma each year. The readmission rates for children over and under 5 years were about $45 \%$ and $58 \%$ (the difference reflects the greater frequency of wheezing attacks in younger children), and there was no overall rising trend. Readmissions, however, did account for some of the initial rise after the introduction of nebulised salbutamol. The rate in children over 5 rose from $43 \%$ in 1976 to about $60 \%$ in the next three years and then fell. There was a lesser but similar initial trend in the later influx of younger children, mainly affecting those aged 3 or 4 when they first received nebuliser treatment.

There was no artefact due to diagnostic transfer: admissions for wheezy bronchitis remained at a relatively constant and low level, with an increasing tendency over the years for the seasonal pattern to mirror that of bronchiolitis. There was no increase in the proportion of asthmatic children admitted from casualty; it was not, however, possible to determine whether children with milder symptoms were being admitted, as it was not known whether children were presenting with a similar or milder range of disease than previously. The median duration of stay for asthma admissions fell over the period from 4.3 to $2 \cdot 2$ days but the trend was evident before any rise in admissions, and varied with steroid and nebuliser use. Admissions were not drawn from a wider area or from an altered geographic distribution.

\section{PROSPECTIVE STUDY}

There were 605 admissions (407 boys, 198 girls) over the one year period; a further 39 children were sent home from casualty. Out of a total of 455 children, $369(61 \%)$ admissions were of children admitted only once during the study period; 47 children $(10 \%)$ were admitted twice, and $39(9 \%)$ three or more times. The median (1st and 3rd quartile) age was $4 \cdot 2(2 \cdot 4-6 \cdot 9)$ years. Children stayed in hospital for a median three (two to three) days, and received nebulised bronchodilator on a median eight (five to 12) occasions. Additional treatment with steroids was given to 185 out of $605(31 \%)$.

Self referrals accounted for 437 out of $605(72 \%)$ admissions, or 351 out of the $521(67 \%)$ answering the questionnaire. Parents of $284(55 \%)$ of these children had not consulted their general practitioner at any time during the current illness, and of these, $218(77 \%)$ quoted knowledge of an open access policy for asthmatics as their reason for bringing the child to hospital. Most of the remaining consultations were accounted for either by the severity of the child's condition $(5 \%)$, or a reported telephone instruction from the general practitioner to take the child to hospital (9\%).

Altogether 136 admissions were first admissions for asthma. Of these, $116(85 \%)$ had seen their general practitioner earlier in the illness and of these $92(79 \%)$ were referred. Where there had been a previous admission the proportions were 121 out of $385(31 \%)$ and 78 out of $121(64 \%)$. Of the 237 out of $521(45 \%)$ who saw their general practitioner, 197 $(83 \%)$ saw their own practitioner rather than a 
Table Treatment received from general practitioner

\begin{tabular}{lc}
\hline & $\begin{array}{l}\text { No }(\%) \text { of } \\
\text { children treated } \\
(n=160)\end{array}$ \\
\hline Nebuliser (gcheral practitioncr) & $45(28)$ \\
Nebuliser (home) & $16(10)$ \\
Inhaler & $15(9)$ \\
Injection & $7(4)$ \\
Bronchodilator syrup & $35(22)$ \\
Antibiotics & $35(22)$ \\
Cough syrup & $4(3)$ \\
Other & $3(2)$
\end{tabular}

Where more than one treatment was given, only onc was recorded: the order of preference was the same as used in the table.

*Of the 2.37 children who saw their general practitioner 77 received no treatment.

partner or deputy. Only $152(64 \%)$ of the parents remembered being told their child had asthma. Where treatment was given (table) this was thought to be effective in only 51 out of $160(32 \%)$. Nebulised bronchodilator treatment, however, was thought effective in 37 out of the $51(73 \%)$ in contrast with other treatment, which was thought effective in only 14 out of $99(14 \%)$. When the child had not been referred directly to hospital by the general practitioner, the median (1st and 3rd quartile) time interval between general practitioner and hospital consultations was eight (three to 24) hours. Dissatisfaction with treatment and symptomatic deterioration were the main reasons given for not returning.

In seeking medical treatment 253 out of 424 $(60 \%)$ of those without home nebulisers were primarily trying to gain access to nebuliser treatment. This applied to 13 of the $133(10 \%)$ children on their first admission and to 240 out of $291(82 \%)$ of those with previous admissions.

\section{Discussion}

\section{RISING INCIDENCE}

The incidence of asthma has been variously reported as between $(0.1 \%$ and $19 \% .5$ Rates vary with the time of survey and population described, but in particular with definition and method adopted. Rates approach $25 \%$ as the definition is expanded to include children with as few as one or two wheezing episodes. This incidence has shown little change over almost $3($ ) years. (-)

The possibility of a rising incidence of asthma in children of school age was considered as long ago as 1954. ${ }^{11}$ A rise was confirmed by serial studies in Birmingham: $1 \cdot 76 \%$ in $1956-7,5 \cdot 4 \%$ in $1968-9$, and $6.34 \%$ in $1974-5 .^{11}$ The incidence is now thought to be as high as $11 \%{ }^{812}$ Further evidence comes from rising admissions, ${ }^{1-3}$ general practice consultations, ${ }^{13}$ and deaths. ${ }^{1+15}$ It may, however, be the severity rather than the incidence which is rising. A number of environmental changes and their effects may indirectly account for this: warmth and humidity on house mite populations, travel on viral spread, farming practices on pollen and fungal spore release, and motor vehicles and power stations on air pollution, etc. As potential factors are so numerous and may show similar trends, proof may be difficult to obtain, particularly retrospectively.

This study documents an appreciable rise in asthma admissions, a phenomenon that may result from increased incidence, diagnosis, or severity of asthma, but which may also reflect altered referral patterns or expectations of care.

DEFINITION OF ASTHMA

The high incidence of episodic wheezing in early life, and the tendency for this apparent reaction to viral upper respiratory tract infection to disappear by the age of 5 years, led to a past recommendation not to regard such children as asthmatic. ${ }^{16}$ The problem of definition, however, remains as there is no clear dividing line between asthmatic and nonasthmatic wheezing. ${ }^{12}$ The likelihood is that early wheezing is part of the already wide range of disease known as asthma. ${ }^{17}$ Children are prone to viral infections, in asthmatic children these provoke episodic wheezing, and much confusion has resulted. The quest for a formula indicating which children will grow out of their asthma may likewise prove a false goal, ${ }^{9} 18$ as it is now known that many of these children have persistent abnormalities of lung function and risk developing chronic obstructive lung disease in later life. ${ }^{19} 20$

Definitions of asthma hinge on the concept of reversibility, ${ }^{21} 22$ and in children the impact of the nebuliser, and other effective bronchodilator delivery systems, may have been considerable. The practical diagnosis of asthma has been immensely simplified: if wheezing responds then it is asthma. Theoretical difficulties remain as bronchodilators treat only one component of airway narrowing, ${ }^{23}$ and are known to be less effective in young children. $^{24}$

Conceptual changes such as these may have broadened the definition of asthma. There is no evidence from this or previous studies, however, that diagnostic transfer has caused an apparent rise in asthma admissions. The numbers of children admitted with a diagnosis of bronchitis have always been too small and constant for this to have occurred. The same may not be true, however, for children who wheeze in the community. Many studies have publicised the underdiagnosis and undertreatment of asthma $a^{25} 26$ and the disservice 
provided to parents by not telling them the diagnosis. ${ }^{25}$ The availability of effective treatment may also have resulted in an increased willingness to diagnose asthma.

\section{THE EFFECTS OF NEW MEDICATIONS}

The nebuliser caused a revolution in the inpatient treatment of asthma. After its introduction the use of ineffectual treatment rapidly died out. Steroid use also fell, but inappropriately. It is interesting to speculate that a similar temporary fall in steroid use may have contributed to the rise in asthma deaths which followed the introduction of bronchodilator inhalers in the 1960s. ${ }^{27}$

The yearly change in asthma admission rate was strongly associated with the introduction of nebulised bronchodilator treatment. Because this was an abrupt change, unrelated to environmental and social factors, the chance of a spurious association is reduced. Initially there were increased readmissions, probably as a reaction to the availability of more effective treatment. The increase in readmissions was a temporary phenomenon, and may have been reversed by improvements in outpatient treatment. The possibility of a reduced threshold for admission cannot be excluded, but an explanation is required for the vast increase in numbers of patients presenting to casualty with asthma.

The later part of the rise was characterised by an appreciable rise in the number of preschool children. When viewed separately this rise does not show the same relation with the introduction of hospital nebulisers. Preschool children have the most to gain from nebuliser treatment as few will be able to use inhalers. Their increased admissions may reflect the more gradual acquisition of nebulisers by general practitioners, who still provide the usual route by which children are introduced to hospital.

Nebulised bronchodilator treatment provides rapid symptomatic relief. This may have had the effect of attracting children to hospital; they often tell their parents to bring them when they are wheezy. Because of the likelihood that wheezing will return within a few hours children are usually admitted. Children given a nebulisation by their general practitioner are often subsequently referred to hospital for the same reason. Many have by now learned, however, to bypass their general practitioner and come direct to hospital. This may have been a major cause of the rise in number of asthmatic children seen.

It is clear that parents of asthmatic children are dissatisfied with the treatment they receive from their general practitioners, and in consequence they seek hospital treatment. Once parents and children have experienced treatment in hospital they tend to return. Hospital treatment is seen as superior primarily in respect of providing regular nebulised bronchodilator treatment. Many general practitioners do not possess nebulisers. Only $22 \%$ of children were given nebuliser treatment by their general practitioner; one quarter used the child's own home nebuliser.

Strong preference for nebuliser treatment may also explain the willingness of parents of asthmatic children to travel greater distances to hospital. Although the median (1st and 3rd quartile) distances travelled by self referring parents of asthmatic (3.7; $1 \cdot 8-11.4 \mathrm{~km})$ and other children $(3 \cdot 0 ; 1.5-4.5 \mathrm{~km})$ were similar, the upper quartile for the asthmatic children was very much larger and the two distributions differed very significantly $(p<<0.0001$ Wilcoxon rank sum test).

\section{AGE DISTRIBUTION}

The initial rise in admissions consisted predominantly of school age children, followed later by a greater rise in preschool children. It is unlikely that this represents a change in the pattern of wheezing in the community. Past studies have shown that there are more younger than older children who wheeze, and they do so more often. ${ }^{2 x}$ If the proportion of wheezing episodes resulting in admission has risen, then the age distribution of admissions may increasingly have come to mirror that of wheezing in the community. ${ }^{13}$ The increased presentation of children with a short history of wheezing may have resulted from increased diagnosis or increased public awareness of asthma. Alternatively, improvements in prophylactic treatment and drug delivery systems may have prevented a greater rise in admissions of older children, whereas similar treatment may be impractical or ineffective in preschool children. ${ }^{2+}$

\section{REVERSING THE TRENI)}

Admission for asthma is rarely desirable, although there may be indirect benefits such as peace of mind for all concerned and an opportunity for patient education. Admission is often highly disruptive to family life, and places a strain on hospital resources. It transpires, however, that most patients are self referrals, and many expect admission.

As the major reason for self referral appears to be access to nebuliser treatment, greater provision of nebulisers at home may help reduce admissions. Home nebuliser treatment, however, may not be without risk. ${ }^{29}$ It is highly desirable that more general practitioners should own nebulisers. As few attacks of asthma will remit after a single treatment, nebulisers need to be made available for short term loan. Potential problems are unfamiliarity with the 
machine, and inability of parents of newly diagnosed children to judge deterioration or inadequate response to treatment.

Improved outpatient management may help to reduce admissions, but this is probably already occurring. The main problem is the large number of first admissions, and the large proportion of very young children with asthma in whom administration of treatment may be difficult, and response less satisfactory. Wheezing in children tends to be episodic, and the early use of oral steroids, in conjunction with other treatment, has been shown to be highly effective ${ }^{30}$ There seems to be a great reticence in general practice to use short oral steroid courses and it seems likely that if this attitude could be altered together with acceptance of sensible controlled nebulised bronchodilator treatment in the home many hospital admissions could be avoided.

JS and EB were each supported by a grant from the Royal Alexandra Hospital Centenary Appeal Fund. EB was also supported by a generous grant from Allen and Hanburys Limited.

\section{References}

${ }^{1}$ Anderson HR, Bailey P, West S. Trends in the hospital care of acute asthma 1970-8: a regional study. $\mathrm{Br}$ Med J 1980;281: 1191-4.

${ }^{2}$ Khot A, Burn R, Evans N, Lenney C, Lenney W. Seasonal variation and time trends in childhood asthma in England and Wales 1975-81. Br Med J 1984;289:235-7.

${ }^{3}$ Mitchell E. International trends in hospital admission rates for asthma. Arch Dis Child 1985;60:376-8.

${ }^{4}$ Anderson HR. Increase in hospitalisation for childhood asthma. Arch Dis Child 1978;53:295-300.

${ }^{5}$ Gregg I. Epidemiological aspects. In: Clarke TJH, Godfrey S, eds. Asthma. 2nd ed. London: Chapman and Hall, 1983:242-84.

${ }^{6}$ Goodall JF. The natural history of common respiratory infection and some principles in its management. III. Wheezy children. $J$ Coll Gen Pract 1958;1:51-9.

${ }^{7}$ Leeder SR, Corkhill RT, Irwig LM, Holland WW, Colley JRT. Influence of family factors on asthma and wheezing during the first five years of life. British Journal of Preventive and Social Medicine 1976;30:213-8.

${ }^{8}$ Anderson HR, Bailey PA, Cooper JS, Palmer JC, West S. Morbidity and school absence caused by asthma and wheezing illness. Arch Dis Child 1983;58:777-84.
" Park ES, Golding J, Carswell F, Stewart-Brown S. Preschool wheezing and prognosis at 10. Arch Dis Child 1986;61:642-6.

10 Kraepelien S. The frequency of bronchial asthma in Swedish school children. Acta Paediatrica 1954:43(suppl 100):149-53.

1 Morrison Smith $\mathbf{J}$. The prevalence of asthma and wheezing in children. Br J Dis Chest 1976;70:73-7.

12 Lee DA, Winslow NR, Speight ANP, Hey EN. Prevalence and spectrum of asthma in childhood. Br Med J 1983;286:1256-8.

13 Fleming DM, Crombie DL. Prevalence of asthma and hay fever in England and Wales. Br Med J 1987;294:279-83.

${ }^{14}$ Mellis CM, Phelan PD. Asthma deaths in children-a continuing problem. Thorax 1977;32:29-34.

15 Khot A, Burn R. Seasonal variation and time trends of deaths from asthma in England and Wales 1960-82. Br Med $J$ 1984:289:233-4.

16 Illingworth RS. The child with chronic allergy. The Practitioner 1955;174:414-21.

17 McNicol KN, Williams HE. Spectrum of asthma in children-I, clinical and physiological components. Br Med J 1973;267:7-11.

${ }^{18}$ Williams HE, McNicol KN. The spectrum of asthma in children. Pediatr Clin North Am 1975;22:43-52.

19 Martin AJ, Landau LI, Phelan PD. Lung function in young adults who had asthma in childhood. Am Rev Respir Dis 1980;122:609-16.

${ }^{20}$ Pride N. Smoking, allergy and airways obstruction: revival of the 'Dutch hypothesis'. Clin Allergy 1986;16:3-6.

${ }^{21}$ Scadding JG. Definitions and clinical categories of asthma. In: Clarke TJH, Godfrey S, eds. Asthma. 2nd ed. London: Chapman and Hall, 1983:1-11.

22 Godfrey S. What is asthma? Arch Dis Child 1985;60:997-1000.

${ }^{23}$ Aas K. Allergic asthma in childhood. Arch Dis Child 1969;44: 1-10.

${ }^{24}$ Lenney W, Milner AD. At what age do bronchodilator drugs work? Arch Dis Child 1978;53:532-5.

${ }^{25}$ Speight ANP, Lee DA, Hey EN. Underdiagnosis and undertreatment of asthma in childhood. Br Med $J$ 1983;286:1253-6.

${ }^{26}$ Conway SP, Littlewood JM. Admission to hospital with asthma. Arch Dis Child 1985;60:636-9.

${ }^{27}$ Inman WHW, Adelstein AM. Rise and fall of asthma mortality in England and Wales in relation to use of pressurised aerosols. Lancet 1969;ii:279-85.

28 Williams HE, McNicol KN. Prevalence, natural history and relationship of wheezy bronchitis and asthma in children; an epidemiological study. Br Med J 1969;iv:321-5.

29 Sears MR, Rea HH, Fenwick J; et al. 75 deaths in asthmatics prescribed home nebulisers. Br Med J 1987;294:477-80.

30 Storr J, Barrell E, Barry W, Lenney W, Hatcher G. Effect of a single oral dose of prednisolone in acute childhood asthma. Lancet 1987;i:879-82.

Correspondence to Dr W Lenney, Royal Alexandra Hospital for Sick Children, Dyke Road, Brighton, East Sussex BN1 3JN.

Accepted 18 January 1988 